\title{
Influence of Modified ZnO Quantum Dots and Nanostructures as New Antibacterials
}

\author{
Zahra Fakhroueian ${ }^{1 *}$, Faraz M. Harsini ${ }^{2}$, Firoozeh Chalabian ${ }^{3}$, Fatemeh Katouzian ${ }^{4}$, \\ Azizollah Shafiekhani ${ }^{5,6}$, Pegah Esmaeilzadeh ${ }^{7}$ \\ ${ }^{1}$ School of Chemical Engineering, College of Engineering, University of Tehran, Tehran, Iran \\ ${ }^{2}$ Department of Biotechnology, School of Chemical Engineering, University of Tehran, Iran \\ ${ }^{3}$ Department of Biology, Azad University, Tehran, Iran \\ ${ }^{4}$ Department of Microbiology, Azad University, Tehran, Iran \\ ${ }^{5}$ Physics Department, Alzahra University, Tehran, Iran \\ ${ }^{6}$ School of Physics, IPM, Tehran, Iran \\ ${ }^{7}$ Biomedical Material Department, Institute of Pharmacy, Martin Luther University, Halle-Wittenberg, Germany \\ Email: *fakhroueian@ut.ac.ir
}

Received April 25, 2013; revised May 25, 2013; accepted June 4, 2013

Copyright (C) 2013 Zahra Fakhroueian et al. This is an open access article distributed under the Creative Commons Attribution License, which permits unrestricted use, distribution, and reproduction in any medium, provided the original work is properly cited.

\begin{abstract}
Antibacterial activities of various spherical zinc oxide nanoparticles and nano special morphological structures including quantum dots, nanorod arrays, nanoporous shapes and needle-like crystals had been investigated as new nanomedicine compounds. Also antibacterial activity based on minimal inhibitory concentration and the growth inhibitory zone (well method) was evaluated. $\mathrm{ZnO}$ nanostructures were fabricated by novel hydrolysis sol-gel-hydrothermal process followed with rapid quenching as new technique using glycerine, vegetable fatty esters such as coconut, sunflower and Lauric alcohol ethoxylated as organic templates soluble in eco-friendly nanofluids. The results showed that Bacillus anthracis and Pseudomonas aerogenes were extremely sensitive to treatment with unique $\mathrm{ZnO}$ nanostructured. Their growth inhibitory zone presented $30 \mathrm{~mm}$ and $25 \mathrm{~mm}$ inhibition zone with better inhibitory effect compared to the Gentamicin antibiotic standard. $\mathrm{ZnO}$ nanostructures had also been indicated to have a wide range of antibacterial activities against both Gram-positive and Gram-negative bacteria especially more effective on $(\mathrm{gr}+)$ species using the growth inhibitory zone. We could design and make significant formulations of fatty acids and esters-capped $\mathrm{ZnO}$ quantum dots nanofluids which created high promising agents for controlling Anthrax, Staphylococcus epidermidis and their influences in antimicrobial properties with low cost for future.
\end{abstract}

Keywords: Nanobiotechnology; Antibacterial Activity; Hydrolysis Sol-Gel-Hydrothermal; ZnO Quantum Dots; MIC and Well Method; Complex Defects

\section{Introduction}

Strong luminescence material zinc oxide including hexagonal wurtzite crystal is a wide band gap $(3.37 \mathrm{eV})$ semiconductor with a large excitation binding energy and an exciton Bohr radius in the range of $1.4-3.5 \mathrm{~nm}$ [1] and is a commercially important material used in paints, rubbers, concrete, electronics, lasers, transistors, photodetectors, gas and biosensors, piezoelectric and solar cells, optoelectronics, photocatalysts, cosmetic, biomedicine, food industry, anticorrosive coating, antibacterial and antifungal agents. These wide varieties of prominent applications require the fabrication of special morphological and functionalization of $\mathrm{ZnO}$ nanostructures sur-

${ }^{*}$ Corresponding author. face [2-4]. In fact, if we are able to modify the surface of $\mathrm{ZnO}$ nanoparticles, the most of their excellent properties will wonderful be obvious. Many efforts have been made to synthesize $\mathrm{ZnO}$ with various morphologies, including nanorods, nanowires, nanorings, nanoflowers, nanospherical, nanotubes, nanodisks, nanodumbbells, nanoneedles, nanowhiskers, nanonail, nanobelts, nanosheets, nanosprings, nanoribbon and many more by self-assembly of nanoscaled building blocks $[5,6]$. To achieve these interesting morphologies there are many different preparing techniques for synthesis of $\mathrm{ZnO}$ nanostructures such as direct precipitation, spray pyrolysis, microemulsion, the hydrothermal treatment, sol-gel process using surfactant additive as templates (chemical hydrolysis), wet-chemical 
procedure, audible sound method, hydrothermal microwave heating, flame spray pyrolysis (FSP), high-temperature methods, chemical vapor deposition (CVD), molecular beam epitaxy (MBE) [7], and finally the particular rapid cold or hot annealing quenching sol-gel method (cold and thermal shock) for producing of new quantum dots $\mathrm{ZnO}$ nanostructures.

Quantum-sized nanodots $\mathrm{ZnO}$ represents a unique class of zero-dimensional nanostructures which can generate novel properties that differ from those of their bulk crystals due to their small sizes and large surface-to-volume ratios [8]. In the quantum-size region, the absorption of UV or visible light strongly depends on their size, shape, kind of fabrication conditions and techniques, temperature of calcination, annealing condition and aging time, presence of dopants and on PVP (polyvinylpyrrolidone) or green fatty acids coating. Actually, these key factors are able to produce n-type semiconductor containg the measured of direct band gap in quantum-dots $\mathrm{ZnO}$ nanoparticles. On the other hand, the visible emission is mainly attributed to the surface or structural defects of the crystal, resulting in large variations in the emission peaks [8]. The existence of certain defect complexes such as $\mathrm{V}_{\mathrm{Zn}}-\mathrm{H}_{\mathrm{i}}, \mathrm{O}-\mathrm{H}$, and $\mathrm{Zn}-\mathrm{H}_{\mathrm{O}}$ has advantages over the pure semiconductor and quantum dots $\mathrm{ZnO}$ nanostructures [9] and a wide visible-emission at the deep level defect in the $\mathrm{ZnO}$ nanoparticles (NPs) are due to the existence of cationic $\mathrm{Zn}$ vacancies $\left(\mathrm{V}_{\mathrm{Zn}}\right)$, oxygen vacancies $\left(\mathrm{V}_{\mathrm{O}}\right), \mathrm{Zn}$ interstitials $\left(\mathrm{Zn}_{\mathrm{i}}\right)$, charge defects, surface defects and their complex defects [10].

Semiconductor quantum dots (QDs) have shown unique optical properties, strong photoluminescence (PL) emission and potential applications in biological fluorescent labels like CdSe and CdTe QDs [11] and $\mathrm{ZnO}$ as a nontoxic and cheap luminescent material is a promising candidate as antibacterial agent and several mechanisms have been proposed for this evidence [12] which is considered to be due to the induction of intercellular reactive oxygen species, including $\left(\mathrm{H}_{2} \mathrm{O}_{2}\right)$ from its surface as a strong oxidizing agent harmful to bacterial cells which can penetrate into the cell membrane $[13,14]$. The high rate of generation of surface oxygen species from $\mathrm{ZnO}$ leads to the death of the bacteria. There are some reports on the considerable antibacterial activity of $\mathrm{TiO}_{2}, \mathrm{MgO}, \mathrm{CaO}, \mathrm{SiO}_{2}$ and $\mathrm{ZnO}$ [15] which is attributed to the generation of reactive oxygen species on the surface of these inorganic oxides owing to they contain mineral elements essential to humans and exhibit strong activity even when administered in small amounts. Another possible mechanism for $\mathrm{ZnO}$ antibacterial activity is the release of $\mathrm{Zn}^{2+}$ ions. It is well known that $\mathrm{ZnO}$ normally becomes unstable in the solution, and when $\mathrm{H}_{2} \mathrm{O}_{2}$ is produced, the $\mathrm{Zn}^{2+}$ ion concentration is increased as a result of $\mathrm{ZnO}$ decomposi- tion [16]. Quantum dots (QDs) $\mathrm{ZnO}$ nanoparticles have shown strong activity against some of Gram- positive and Gram-negative bacteria and biocompatibility with colloidal semiconductor luminescent inorganic materials [17] and a promising member of the Cd-free QD family is $\mathrm{ZnO}$ nanoparticles. Functionalization and treat- ment of $\mathrm{ZnO}$ quantum Dots with polymers, organosilanes and vegetable fatty acids is able to modify the surface of QDs $\mathrm{ZnO}$. Nanospherical, nanorods, nano-porous $\mathrm{ZnO}$ and nanowire morphologies could be used as effective bactericidal materials against both Gram-positive and Gramnegative bacteria. $\mathrm{ZnO}$ quantum dot nanoparticles containing polymer templates (PVP, PEG, PVA, polystyrene) and oleic acid treatment will be promising candidate as interesting nanodrug-carriers and also new antibacterial agents. $\mathrm{ZnO}$ is one of five zinc compounds that are currently listed as generally recognized as safe by the U.S. Food and Drug Administration (21CFR182.8991). Antimicrobial efficacy of zinc oxide quantum dots contain polystyrene and PVP as active antibacterials against some of bacteria was investigated in culture media and liquid egg white [3] and was found that the functionalization and treatment of surface can produce significant results. The availability of $\mathrm{ZnO}$ QDs in media was important for antibacterial efficiency. They even have antibacterial activity against spores that are resistant to high temperature and high pressure and parameters such as size of $\mathrm{ZnO}$ nanoparticles, larger the surface area, crystalline structure, particle shape, concentration, time, temperature and combination with other bacteriocins (synergistic effect) will be the focus of further study. However, the anticancer property of $\mathrm{ZnO}$ nanoparticles is an undeveloped area that is of potential medical interest in future [18-22].

In the present study, three various groups of $\mathrm{ZnO}$ nanostructures such as nanoparticles, quantum dots, and modified surface compounds using polymers, vegetable fatty acids, coconut, sunflower esters have been synthezied and also $\mathrm{ZnO}$ nanoparticles doped silica-substrate was made. We believe that they can generate strong nanoporous surfaces liable to do chemical reactions with live bacteria. Also the types of nanospherical, nanorods and nanoporous $\mathrm{ZnO}$ morphologies could be characterized. It was also found that the size of the quantum dots could be tailored by controlling the process parameters aligned with additional surfactants, stabilizers, suitable solvents or capping agents. Audible sound method and sol-gel hydrothermal microwave process were carried out for synthesis of $\mathrm{ZnO}$ nanostructure and antibacterial activities against both gr+ and gr- bacteria were successfully investigated by well method and MIC test. Potential applications of $\mathrm{ZnO}$ QDs and treatment products were observed for most of both strong microorganisms for the first time. 


\section{Experimental Details}

All chemicals are analytical grade and are used as received without further purification.

\section{Preparation of ZnO Nanostructures by Sol-Gel Process, Wet-Chemical Procedure, Audible Sound and Hydrothermal Microwave Method}

Sample 1: 0.03 mole zinc acetate dihydrate $\mathrm{Zn}$ $\left(\mathrm{CH}_{3} \mathrm{CO}_{2}\right)_{2} \cdot 2 \mathrm{H}_{2} \mathrm{O}$ in $15-20 \mathrm{ml}$ isopropanol solution was dissolved (solution A). $10 \mathrm{ml}$ coconut fatty glycerine ester-PEG was added and heated. The resultant coldmixture containg of isopropanol, glycerine and LA7EO (Lauryl alcohol 7 mole ethoxylate) was prepared (solution B). Solution A was added to solution B under the rapid cold quenching and was hydrolyzed with $20 \%$ $\mathrm{NaOH}$ solution under vigorous stirring and was kept at $0^{\circ} \mathrm{C}$. After the mixing, they were heated to reflux quickly at $70^{\circ} \mathrm{C}-85^{\circ} \mathrm{C}$ in the hot bath. The product was washed and filtered and finally dried at $100^{\circ} \mathrm{C}$ in oven and subsequently calcined at $850^{\circ} \mathrm{C}$.

Sample 2: The sample 1 was washed and filtered several times with $\mathrm{H}_{2} \mathrm{O} / \mathrm{ethanol}(1: 1 \mathrm{v} / \mathrm{v})$ solution. The obtained sol was dried in hot air oven at $90^{\circ} \mathrm{C}$ for $48 \mathrm{~h}$ further the white powder was calcined at $700^{\circ} \mathrm{C}$ again for 6 $\mathrm{h}$ to form $\mathrm{ZnO}$ nanocrystals.

Sample 3: This product is the same as the sample 1, but we used cold 1, 2-propylene oxide $\left(\mathrm{C}_{3} \mathrm{H}_{6} \mathrm{O}\right)$ nonionic surfactant instead of coconut fatty glycerine ester-PEG and 0.6 gr. hydroxy propyl cellulose (J-type) as stabilizer with 2 gr. starch in white powder before of calcination process.

Sample 4: Audible sound is produced by sound pressure applied to a listener's ear. The pressure is initiated by some mechanical devices like speakers that create a series of pulses of energy which cause air molecules to vibrate. The sol-gel method was made using of zinc acetate dihydrate which hydrolyzed by cold $\mathrm{NaOH}$ solution like sample 3, then audible sound method was carried out under the specific frequency of $11,100 \mathrm{~Hz}$ and intensity of $115 \mathrm{~dB}$ in hot bath at $70^{\circ} \mathrm{C}-80^{\circ} \mathrm{C}$ during 3 days at sonic condition. This frequency was selected to produce the maximum intensity which is possible for our devices. The audible sound with this condition was performed above the nanoparticles suspension vessel.

Sample 5: 0.0095 mole zinc acetate dihydrate merck company was hydrolyzed by 4.5 gr. $\mathrm{KOH}$ solution containg $200 \mathrm{ml}$ mixture of isopropanol, methanol, ethanol and water. Then the solution of PEG-6000 and 1 gr. PVP (polyvinyl pyrrolidone) was added meanwhile the hydrolyzing reaction was occurring. The yellow precipitation appeared after stirring for $2 \mathrm{~h}$ at $70^{\circ} \mathrm{C}-85^{\circ} \mathrm{C}$. Then the product was evaporated and dried in oven. Final product dissolved in mixture of hexane and alcohols and was kept at $0^{\circ} \mathrm{C}$ until the $\mathrm{ZnO}$ QDs were fully precipitated and settled. After the removal of the supernatant it was ready to be calcined at $850^{\circ} \mathrm{C}$. The obtained white product was washed with the mixture of alcohols several times and filtered and dried at $85^{\circ} \mathrm{C}$ and was annealed at $700^{\circ} \mathrm{C}$ again.

Sample 6: This product was fabricated the same as sample 5 using of audible sound method including the frequency of $150 \mathrm{~Hz}$ and the intensity of $94 \mathrm{~dB}$ This special frequency had been chosen because of its high ability to produce visible vibration at nanoparticles suspension. Finally the suspensions were left for 7 days under sonic exposure.

Sample 7: The surface of $\mathrm{ZnO}$ nanoproduct was modified by doped silica-substrate using coprecipitation method. The mixture of 0.2 mole zinc acetate dihydrate and 0.8 mole TEOS (tetraethyl orthosilicate) were dissolved in alcohol solution including oleic acid as stabilizer. The $\mathrm{pH}$ was adjusted at $10-11$ with cold $\mathrm{NaOH}$ and ethylene diamine solution by drop wise until the solution reaches a suitable $\mathrm{pH}$. After the hydrothermal process at $90^{\circ} \mathrm{C}$ for 4 days, the yellow powder precursor became ready to calcine at $850^{\circ} \mathrm{C}$.

Sample 8: Oleic acid-capped $\mathrm{ZnO}$ Q-Dots was fabricated by sol-gel method using zinc acetate dihydrate (1.2 mmole) in ethanol, LA3 (Lauryl alcohol 3 mole ethoxylated) as surfactant was mixed below $50^{\circ} \mathrm{C}$ under vigorous stirring. Around the 10 - 20 gr. oleic acid in alcohol was added during the reflux of mixture. The hydrolysis reaction was carried out with TBAH reagent (tetrabutylammonium hydroxide) in ice bath at $0^{\circ} \mathrm{C}$. After dissolving the precipitation, $\mathrm{pH}$ value was changed to acidic and supernatant was evaporated at $60^{\circ} \mathrm{C}$, and the soluble product in oleic acid was appeared.

Samples 9, 10 and 11: In this synthesis the sol-gel method was carried out for hydrolysis of $0.2 \mathrm{M}$ zinc acetate dihydrate in isopropyl alcohol with $0.4 \mathrm{M} \mathrm{NaOH}$ solution at pH 10 - 11 in appearance of TEA (three ethanolamine), EDA (ethylene diamine) and citric acid as template-assisted. The mixture was heated to reflux at $85^{\circ} \mathrm{C}$ for $8 \mathrm{~h}$. The white crystalline $\mathrm{ZnO}$ nanoparticles appeared after the filtration, washing, drying and calcination at $850^{\circ} \mathrm{C}$.

Samples 12, 13 and 14: Sample 12 was fabricated using LA3EO (Lauryl Alcohol 3 moles EO) and nonylphenol 10-EO by sol-gel method and further cold quenching. sample 13 was synthesized by sol-gel, hydrothermal process including PEG6000 and PVP as capped polymer templates by fast cold quenching method and calcined at $850^{\circ} \mathrm{C}$ only once. Finally, sample 14 was synthesized by cold sol-gel method in alkaline condition using tetra butyl ammonium hydroxide (TBAH) containing NON9EO (nonylphenol 9 moles ethoxylated) contains 1,2-propylene oxide as nonionic surfactant. 


\section{Results and Discussion}

\subsection{SEM Pictures of QDs and ZnO Nanoparticles According to the Symbol Samples}

For sample 1 in Figure 1.

For sample 2 in Figure 2.

For samples (a) extended nanoparticles of 3 and (b) nanosphericals 4 in Figure 3.

For nanorods as nanowhiskers or nanoflowers $\mathrm{ZnO}$ QDs samples 5 and 13 in Figure 4.

For samples (a) $\mathrm{ZnO}$ nanoparticles of sample 6 and (b) nanoparticles of sample 7 in Figure 5.

For samples (a) $\mathrm{ZnO}$ nanorods which are dispersed in oleic acid for sample 8, (b) sample 10, (c) very homogeneous nanospherical of sample 11 and (d) $\mathrm{ZnO}$ QDs of sample 12 in Figure 6.

\subsection{XRD Patterns of $\mathrm{ZnO}$ Nanostructures (Samples 2, 5 and 11)}

The XRD patterns of the three products demonstrate that all of the diffraction peaks can be indexed as typical hexagonal phase of $\mathrm{ZnO}$ for samples 2 and 5 including space group p63 mc, but the sample 11 showed Wurtzite structure with hexagonal phase according to lattice constant of $\mathrm{a}=\mathrm{b}=3.249 \AA$ and $\mathrm{c}=5.206 \AA$ with JCPDS card no. 36 - 1451. These peaks at scattering angles $(2 \theta)$ correspond to the reflection from: (100), (002), (101), (102), (110), (103), (200) and finally (112) crystal planes respectively. Figure 7 shows XRD patterns of $\mathrm{ZnO}$ nanoparticles for nanorods of samples 2 and 5 and nanospherical for sample 11 [2,7,23-25].

\section{FTIR Spectroscopy of Three ZnO Nanostructures}

FTIR spectrum of $\mathrm{ZnO}$ in $\mathrm{KBr}$ matrix showed a broad
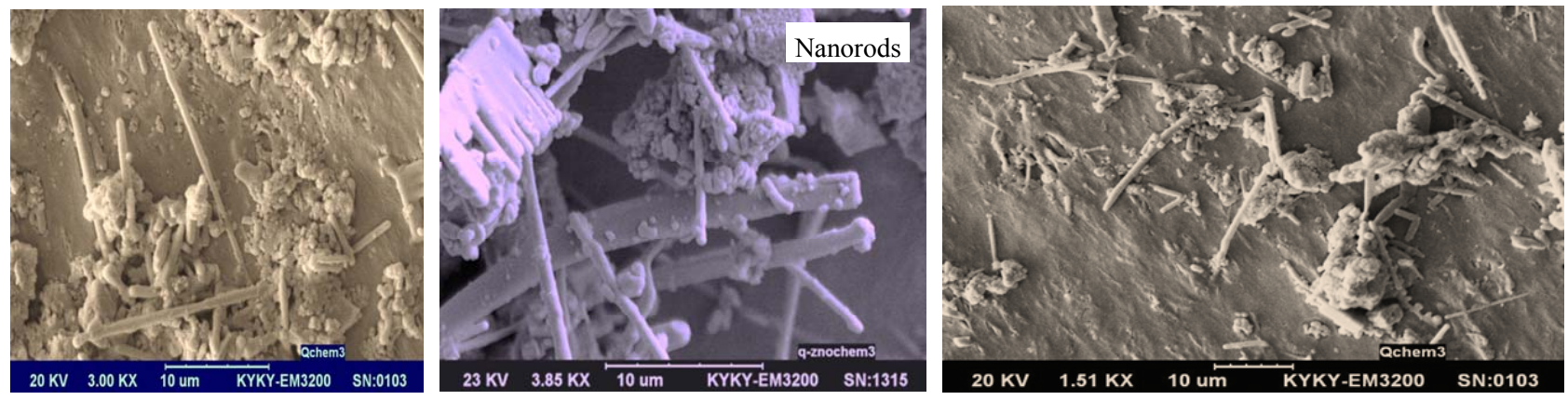

Figure 1. SEM images of QDs ZnO nanorods for sample 1.
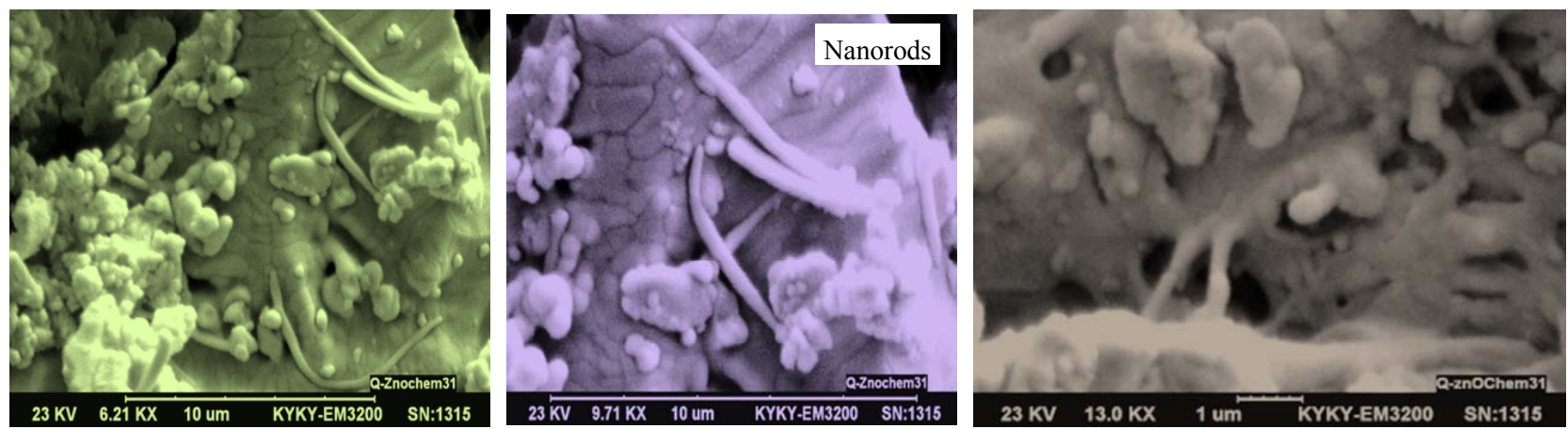

Figure 2. SEM images of QDs ZnO nanorods for sample 2.
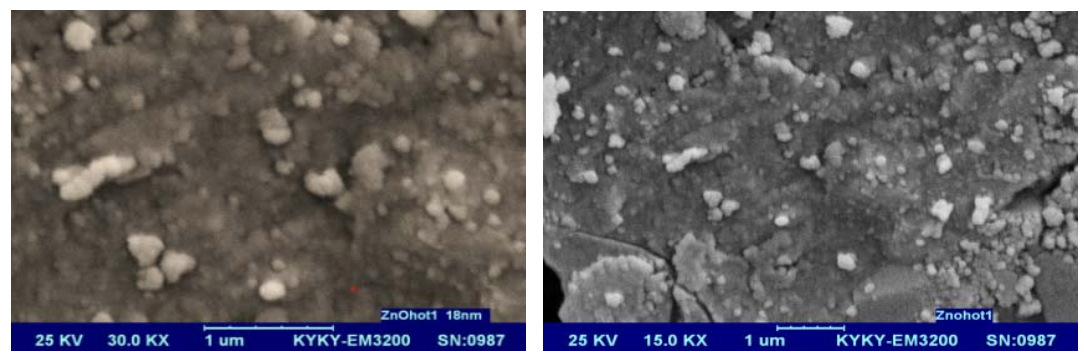

(a)

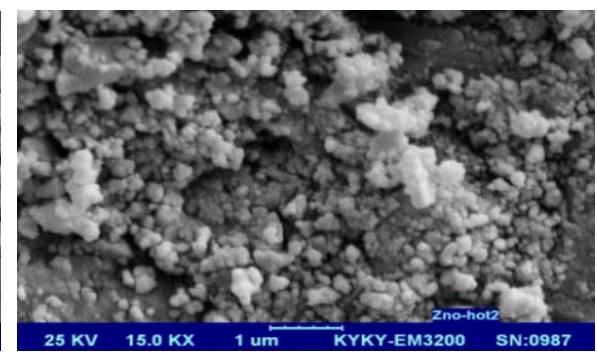

(b)

Figure 3. SEM images of QDs ZnO nanoparticles for (a) sample 3 and (b) sample 4. 

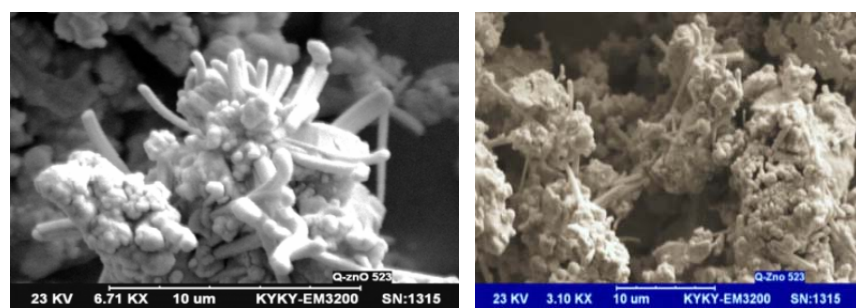

(a)

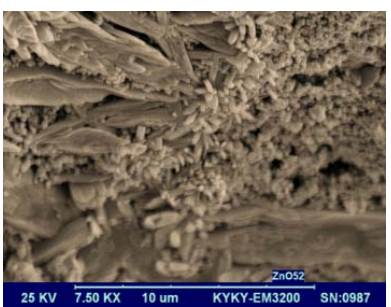

(b)

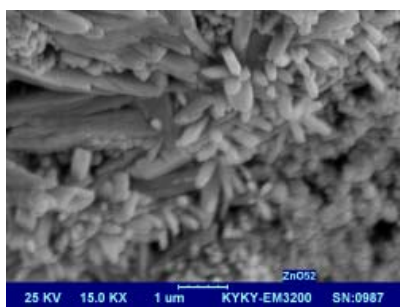

Figure 4. SEM images of nice formation of QDs ZnO nanorods for (a) sample 5 and (b) nanorods-nanoflowers mixture sample 13.
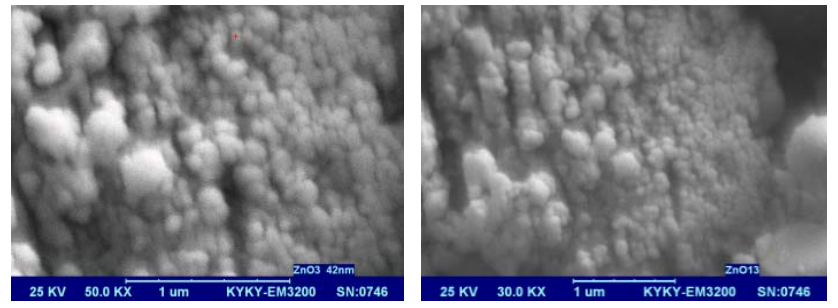

(a)

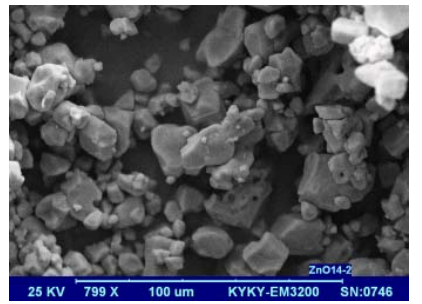

(b)

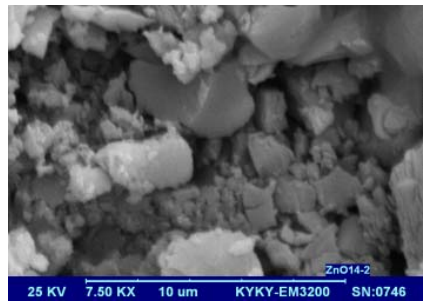

Figure 5. SEM images of two ZnO nanoparticles for (a) homogeneous of sample 6 and (b) sample 7.

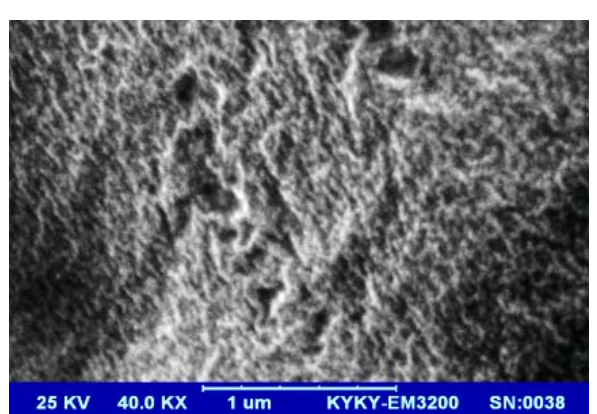

(a)

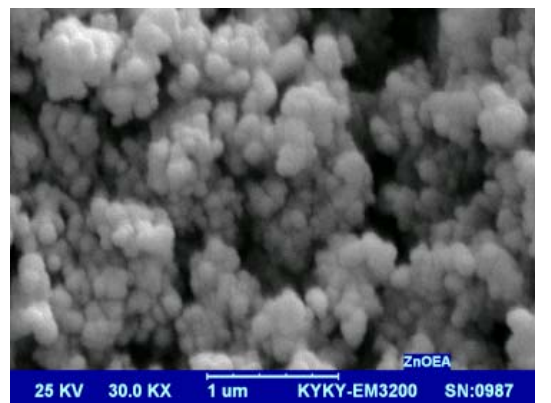

(b)

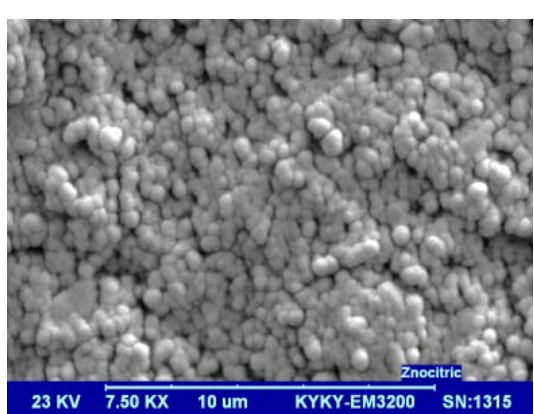

(c)
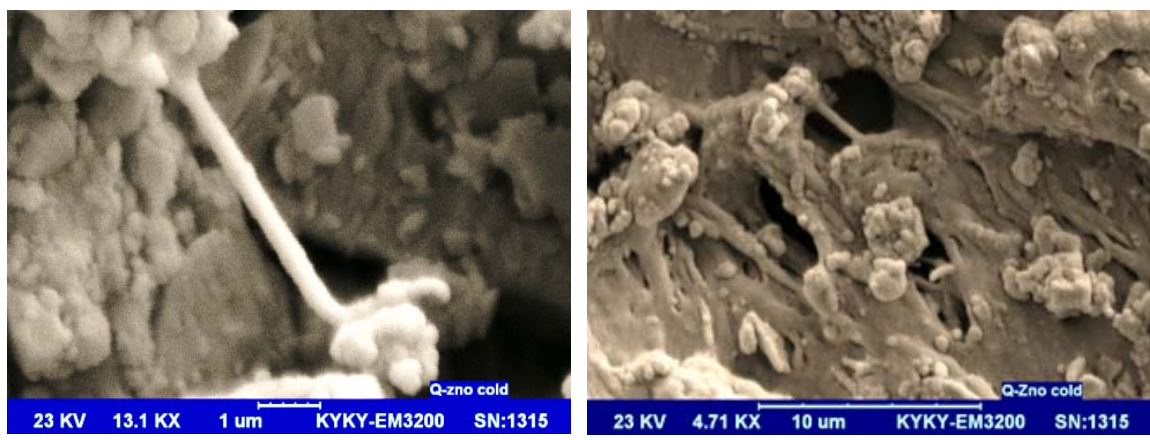

(d)

Figure 6. SEM images of various $\mathrm{ZnO}$ nanostructures for (a) ZnO QDs of sample 8; (b) sample 10; (c) sample 11 and (d) ZnO QDs as nanorods (nanotubes) for sample 12.

band with very low intensity at $3326.83 \mathrm{~cm}^{-1}$ corresponding to the vibration mode of water $-\mathrm{OH}$ group, the band at $1653.19 \mathrm{~cm}^{-1}$ is due to the $\mathrm{OH}$ bending of water. A strong band at $689 \mathrm{~cm}^{-1}$ is attributed to the $\mathrm{Zn}-\mathrm{O}$ stretching band which is indicated in Figure 8.

Two sharp peaks at 920 and $956 \mathrm{~cm}^{-1}$ showed $\mathrm{OH}$ twisting vibrations and lattice $\mathrm{Zn}-\mathrm{H}_{\mathrm{O}}$ for samples 2 and 5 .
These sharp peaks are related to substitutional hydrogen at oxygen site $\mathrm{H}_{\mathrm{O}}$ bond to the lattice $\mathrm{Zn}$ site $\left(\mathrm{Zn}-\mathrm{H}_{\mathrm{O}}\right)$ [9]. The strong peak at $1374 \mathrm{~cm}^{-1}$ is also visible, indicating that -COO groups are not completely removed in sample 11 [26]. The low frequency at $600-800 \mathrm{~cm}^{-1}$ is attributed to hydride $\mathrm{Zn}-\mathrm{H}$ bending modes for sample 11 ( $\mathrm{ZnO}$ citric acid). 


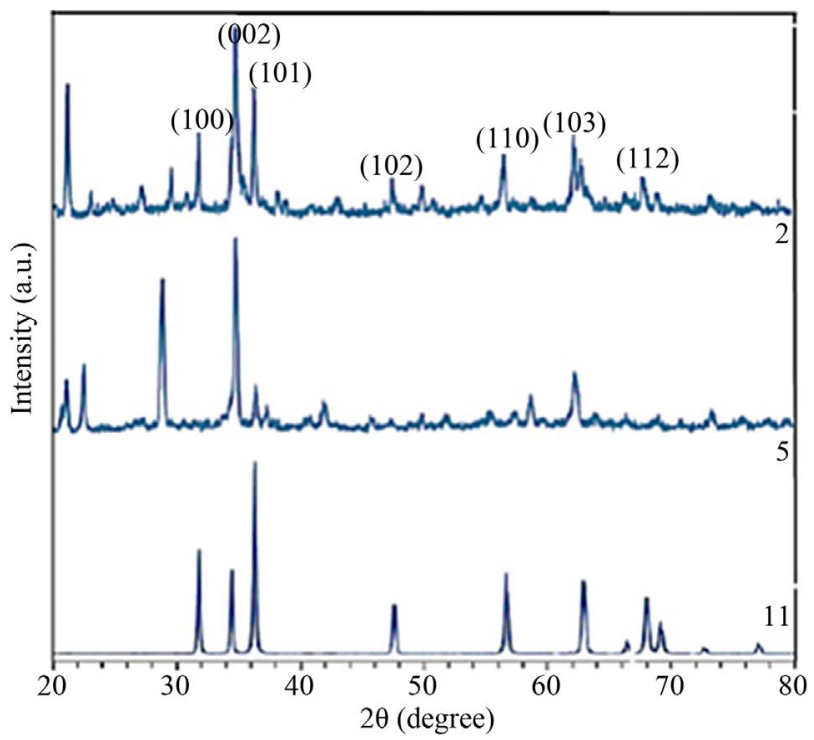

Figure 7. XRD patterns of three $\mathrm{ZnO}$ nanoparticles for nanorods of samples 2 and 5 and nanospherical of sample 11.

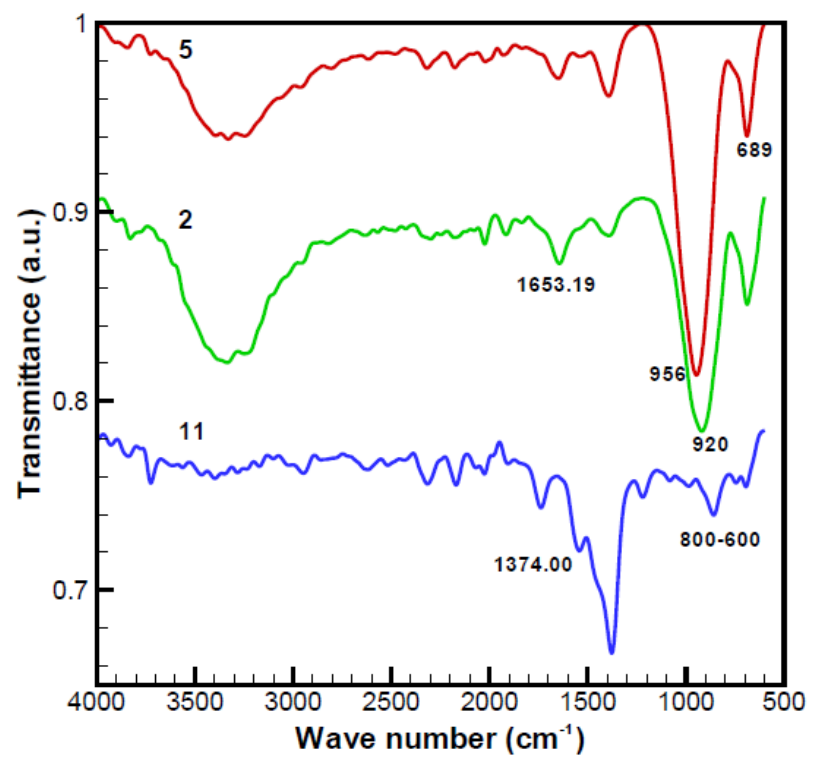

Figure 8. FTIR spectra of three ZnO nanoparticles for nanorods of samples 5 and 2 and nanospherical of sample 11 respectively.

\subsection{UV-Vis Absorbance Spectrum for Several of ZnO Nanoparticles}

Optical absorption studies of the prepared crystalline series of new nanoparticles colloids were carried out as very intense peaks and expanded portion of them at interval of $350-372 \mathrm{~nm}$ and their unique trapping states at $400-700 \mathrm{~nm}$ which are usually attributed to the point defects similar to complex or structural defects for instance of singly ionized oxygen vacancies, zinc vacancies, and surface defects in especial structures of QDs-

\section{$\mathrm{ZnO}$ (Figure 9) $[8,23,27]$.}

It seems that surface trapping states were occupied by positively charged oxygen vacancy defects during high annealing temperatures. Therefore, both absorption spectra and emission shows a distinct blue shift under reaction conditions (increase of calcination temperatures during prolonged aging time) [28]. Figure 10 was shown the typical analysis and feature enlargement of UV-Vis absorption spectrum for four QDs ZnO NPs at limited wavelength of 635 - $665 \mathrm{~nm}$ individually. In such circumstance the excitation of electrons from valance band to conduction band happened through these trapping states.

\subsection{Room Temperature Photoluminescence Including Distinct Broad and Deep Level Blue-Shift Spectrum}

Figures 11 and 12 show photoluminescence spectra and unique $\mathrm{ZnO}$ QDTs nanostructures area.

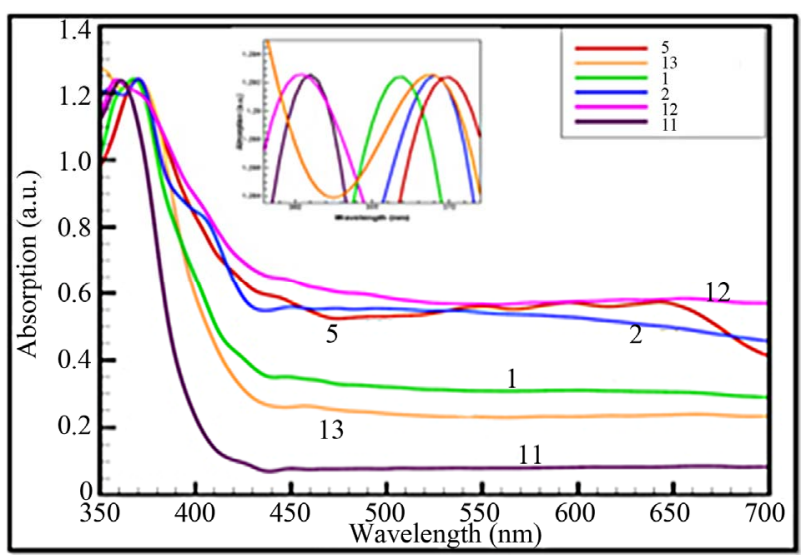

Figure 9. Optical absorption spectra of various QDs ZnO nanorods (samples $5,13,2,12$ ) and nanosphericals (samples 3, 11).

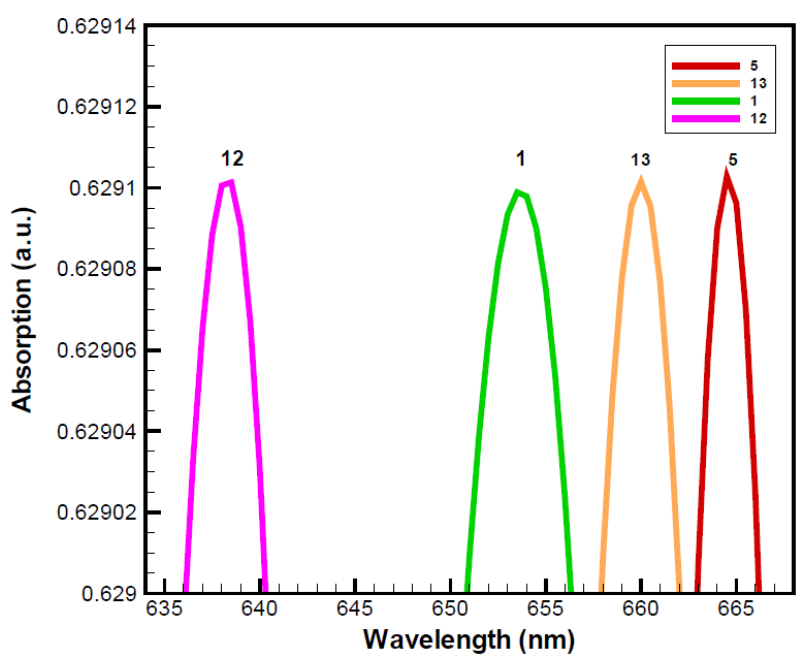

Figure 10. Expansion and analysis of UV-Vis absorption spectra for some QDs ZnO NPs. 

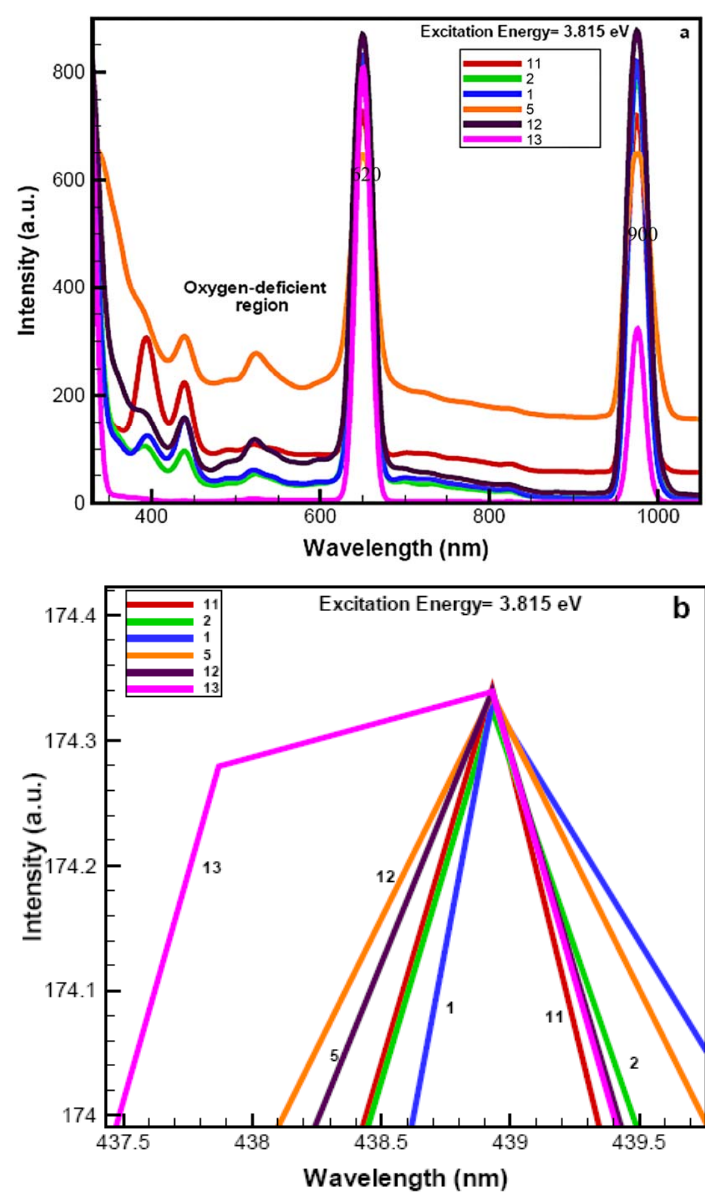

Figure 11. Photoluminescence spectra of (a) various QDs ZnO NPs and (b) the inset shows expansion of limited 437 $439 \mathrm{~nm}$ wavelengths for illustration of broad, ladder and wave-like peaks of especial point defects. All of the products have 620 and $900 \mathrm{~nm}$ wavelength in (a) curve.

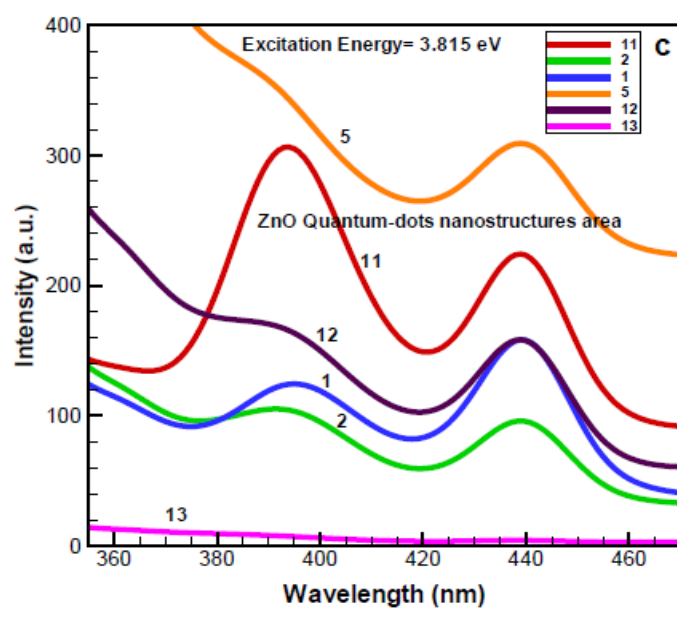

Figure 12. Photoluminescence spectroscopy of (c) some QDs ZnO nanoparticles (No. 11, 2, 1, 5, 12 and 13 from up to down respectively) between especial 360 - $460 \mathrm{~nm}$ wavelengths involving complex defects and expansion deep levels blue shift of products. They showed two different max peaks in two divers regions.
In Figure 12, it was shown photoluminescence spectroscopy in range $360-460 \mathrm{~nm}$ expansion for 6 prepared samples.

The room temperature photoluminescence (PL) spectra with $3.815 \mathrm{eV}$ of excitation energy showed distinct visible emission over a wide span of wavelengths which belongs to the oxygen-deficient region and trapping states from around 350 to $600 \mathrm{~nm}$ for new QDs ZnO nanoparticles (Figure 11(a)). We could expanded especial deep level emissions from 437 to $439 \mathrm{~nm}$ and show them in Figure 11(b). They are signs and causes for influence of complex defects and the kind of their structures [29] on optical blue-shift properties at $850^{\circ} \mathrm{C}-900^{\circ} \mathrm{C}$ annealing temperature [23,25,30,31].

\section{Typical Antibacterial Activity for Evaluating of Various ZnO Nanostructures Introduction to the Gram-Negative and Gram-Positive Bacteria Used in This Study}

For antibacterial tests we could prepare several gramnegative bacteria such as Escherichia coli (RTCC1330), Klebsiella pneumonia (RTCC1249), Pseudomonas aeruginosa (RTCC1547), Enterobacter aerogenes (RTCC1145), Klebsiella pneumonia (RTCC1249) and various grampositive bacteria like: Staphylococcus aureus (RTCC1885), Listeria monocytogenes (RTCC1293), Enterobacter aerogenes (RTCC1145), Bacillus anthracis (RTCC1036), Bacillus anthracis (RTCC1036), Enterococcus faecalis (RTCC2121), Bacillus cereus (RTCC1040) and Staphylococcus epidermidis (RTCC1898).

\subsection{Antibacterial Activity Methods}

Microbial strains: The bacterial strains were cultured in brain heart infusion (BHI, merck) under aerobic condition in $37^{\circ} \mathrm{C}$ for 24 hours on a reciprocal shaker and subculturing was done twice weekly. Suspensions of the organisms were prepared by picking colonies from appropriately incubated agar cultures to sterile broth, to match a McFarland ( barium sulfate standard 0.5) turbidity standard (approximately $\left.1.5 \times 10^{8} \mathrm{CFU} / \mathrm{ml}\right)(\mathrm{McF}$ arland 1907) $[3,13,19,32-35]$.

Well method or agar well diffusion test: The agarwell method was performed as prescribed by NCCLS well. First muller Hinton agar plates were cultured by bacterial suspension. Wells of $5 \mathrm{~mm}$ in diameter were punched the MH agar using a sterile cork-borer about 2 $\mathrm{cm}$ apart. Approximately $100 \mu \mathrm{l}$ of the material suspensions were dropped into each well which filled them respectively to fullness. After incubation at $37^{\circ} \mathrm{C}$ a clear zone around the wells is an evidence for antimicrobial activity. All of these investigations repeated for 24,48 and $72 \mathrm{~h}$. 
Determination of minimum inhibitory concentration (MIC): The minimum inhibitory concentration (MIC) of the extracts was determined according to methods described by CLSI 2006. ZnO suspensions were diluted to concentrations ranging from 100 to $0.78 \mathrm{mg} / \mathrm{ml}$ in Mueller Hinton broth. To each dilution tubes, $0.1 \mathrm{ml}$ of the bacterial inoculum was seeded. Control tubes with no bacterial inoculation were simultaneously maintained. Tubes were incubated aerobically at $37^{\circ} \mathrm{C}$ for 24 hours. The lowest concentration of the extract that produced no visible bacterial growth (turbidity) was recorded as the MIC (CLSI, 2006). To estimate the MIC of the bacteria suspensions more precisely and for confirmation of the results, a more precise concentration in agar dilution method was used $[3,16,20,21,36]$.

\subsection{Evaluation of Methodologies to Determine Antibacterial Activity for Six Q-Dots ZnO Nanoparticles by W. M and MIC Methods Compared with Gentamicin Antibiotic Standard}

Tables 1 and 2 show performance of five and seven vari- ous QDs ZnO nanoparticles including nanorods and nanosphericals structutres against examined Gram negative bacterial strains and the efficiency was compared with standard antibiotic using well diffusion method.

Figure 13 indicates the representation of some agar plates in well method test for sample 5 (Q-ZnO523) against B. cer. (25 $\mathrm{mm}$ zone diameter) and sample 8 (ZnO19) against (b) B. ant (30 mm), (c) St. epi (40 mm) and finally (d) St. au $(30 \mathrm{~mm})$. The presence of an inhibition zone clearly exhibited the significant antibacterial effect of new QDs $\mathrm{ZnO}$ nanostructures on these microbes.

Sample 1 shows strong antibacterial activity against $E$. coli. Sample 3 and sample 5 shows excellent biological activity against Klebsiella pneumonia and also sample 3 is very effective agent against Pseudomonas aeruginosa and all of gr-bacterial strains in Table 1. The results in Table 2 indicates that sample 2 and 3 in the first row shows excellent activity against Bacillus anthracis, and sample 4 illustrates high biological activity against Staphylococcus aureus, and sample 3 showed high activity on the Bacillus cereus. Sample 13 is sensitive to Staphylococcus aureus but sample 5 does not show any influence

Table 1. Effect of five QDs ZnO NPs samples against four Gram negative bacteria with gentamicin standard.

\begin{tabular}{|c|c|c|c|c|c|c|c|}
\hline Gram Negative Bacteria & Method & Samples & 1 & 2 & 3 & 4 & 5 \\
\hline \multirow{2}{*}{ Escherichia coli } & W.M & \multirow{2}{*}{15 mm } & 20 & 10 & 15 & 15 & - \\
\hline & $\mathrm{MIC}$ & & 25 & 100 & 50 & 50 & - \\
\hline \multirow{2}{*}{ Enterobacter aerogenes } & W.M & \multirow{2}{*}{10} & - & - & 20 & 20 & 20 \\
\hline & $\mathrm{MIC}$ & & - & - & 25 & 25 & 25 \\
\hline Klebsiella pneumonia & $\mathrm{MIC}$ & 10 & - & - & 12.5 & 50 & 12.5 \\
\hline \multirow{2}{*}{ Pseudomonas aeruginosa } & W.M & \multirow{2}{*}{10} & 15 & 15 & 25 & $\mathrm{NT}^{*}$ & $\mathrm{NT}^{*}$ \\
\hline & MIC & & 50 & 50 & 12.5 & NT & NT \\
\hline
\end{tabular}

$\mathrm{NT}^{*}=$ was not done.

Table 2. Illustration of seven QDs ZnO NP against six Gram positive bacteria.

\begin{tabular}{|c|c|c|c|c|c|c|c|c|c|}
\hline Gram Positive Bacteria & Method & San & 1 & 2 & 3 & 4 & 5 & 13 & 14 \\
\hline \multirow{2}{*}{ Bacillus anthracis } & W.M & \multirow{2}{*}{$15 \mathrm{~mm}$} & 20 & 30 & 30 & 15 & 15 & - & 15 \\
\hline & $\mathrm{MIC}$ & & 25 & 6.25 & 6.25 & 50 & 50 & - & 50 \\
\hline \multirow{2}{*}{ Staphylococcus aureus } & W.M & \multirow{2}{*}{20} & 20 & - & 15 & 25 & 10 & 20 & 20 \\
\hline & $\mathrm{MIC}$ & & 25 & - & 50 & 12.5 & 100 & 25 & 25 \\
\hline \multirow{2}{*}{ Listeria monocytogenes } & W.M & \multirow{2}{*}{20} & - & - & - & - & - & - & - \\
\hline & $\mathrm{MIC}$ & & - & - & - & - & - & - & - \\
\hline \multirow{2}{*}{ Enterococcus faecalis } & W.M & \multirow{2}{*}{10} & - & 20 & $\mathrm{NT}^{*}$ & - & - & $\mathrm{NT}^{*}$ & - \\
\hline & MIC & & - & 25 & NT & - & - & NT & - \\
\hline \multirow{2}{*}{ Bacillus cereus } & W.M & \multirow{2}{*}{20} & 20 & 10 & 25 & - & 25 & 10 & - \\
\hline & $\mathrm{MIC}$ & & 25 & 100 & 12.5 & - & 12.5 & 100 & - \\
\hline \multirow{2}{*}{ Staphylococcus epidermidis } & W.M & \multirow{2}{*}{20} & - & - & 20 & 15 & - & - & - \\
\hline & $\mathrm{MIC}$ & & - & - & 25 & 50 & - & - & - \\
\hline
\end{tabular}

$\mathrm{NT}^{*}=$ was not done. 


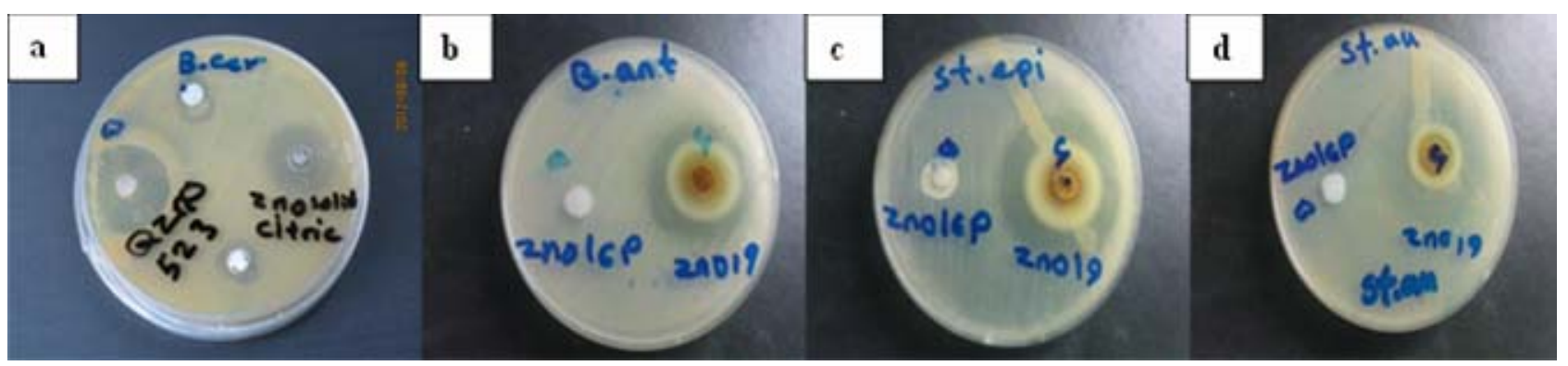

Figure 13. Agar plate test (well method) for (a) sample 5 (with symbol QZnO523) and (b)-(d) sample 8 (with symbol QZnO19) films showing excellent inhibition zone around the films. ZnO16P symbol is the same as sample 8 with polystyrene-capped which it was not successful during the growth process in well test.

against it, whereas they are similar to each other in production stages but are different in purification and calcination process. It was found that, very homogenous nanospherical sample 14 exhibited proper sensitivity related to both Bacillus anthracis and Staphylococcus aureus bacteria. Sample1displaces identical permanent sensitivity responses of the Bacillus anthracis, Staphylococcus aureus and Bacillus cereus. It is promising that we will be able to do treatment and coating its surface owing to bind more strongly to microorganisms. Therefore, by synthesis of these antimicrobial QDs ZnO nanoparticles, we found ideal candidates as antimicrobial agents. Also mechanism of action of $\mathrm{ZnO}$ nanoparticles highlighted that they are capable to kill bacteria through various mechanisms, such as by binding to intracellular proteins and inactivating them, generation of radical and reactive oxygen species including hydrogen peroxide $\left(\mathrm{H}_{2} \mathrm{O}_{2}\right)$, electrostatic interaction between the $\mathrm{ZnO}$ NPs surface and bacteria membranes (cell surfaces) and penetration in and finally via direct damage to cell wall and membrane. Moreover, the key factor is the formation of desired structure and manufacturing of $\mathrm{ZnO} N \mathrm{NPs}$ involve active surfaces with much greater surface area to volume ratio (high BET) to generate defect nanoporous surface (likenanocatalyst) because imperfection nanopores can create active radicals with enough activation energy without dependence upon the crystal size of ZnO NPs and this is very important and notable point in typical present investigation.

In Tables 3 and 4, performance of ZnO NPs groups including audible sound, pretreatments with assistant agents and oleic acid-capped $\mathrm{ZnO}$ Q-Dots products which were tested with gr- and gr+ bacteria is presented.

It is remarkable that three samples are effective against Enterobacter aerogenes in comparison with gentamicin antibiotic reagent in Table 3. Sample 8 illustrated very activity against Klebsiella pneumonia that was modified by oleic acid. Nanospherical of $\mathrm{ZnO}$ which was treated with silica nanoparticles like-square plates morphology in sample 7 showed excellent inhibiting effect against the growth of Pseudomonas aeruginosa and others are sensi- tive comparing to standard antibiotic. In fact this modification method could increase the surface activity of $\mathrm{ZnO}$ nanoparticles to induce proper interactions with microorganisms. Table 4 is capable to report the performance of modified $\mathrm{ZnO}$ NPs by different conditions.

Among all samples in Table 4, sample 8 has high prevent effect on life of Staphylococcus epidermidis and showed the most impressive antibacterial property against mostly Gram Positive bacteria and increased the inhibition zone diameters against all microbes compared with standard antibiotic (W.M $=20 \mathrm{~mm}$ for reference and 40 $\mathrm{mm}$ for sample 8) and good biocompatibility. It seems that the appearance of oleic acid as a development of reliable processes using polymer template type could improve the activity of large surface area available for interaction, binding and diffusion in organ of microbes better resulting into cell death [34]. In addition, sample 7 also showed much activity against the Enterococcus faecalis and Staphylococcus epidermidis and demonstrated excellent activity as an antibacterial agent. Sample 6 is strong antibacterial against Staphylococcus epidermidis. Overall, the results of $\mathrm{ZnO}$ nanoparticles containg organic templates such as TEA, EDA and citric acid were appeared which were not highly against some of the tested pathogens and did not undergo obvious modification on the surface of the $\mathrm{ZnO}$ nanostructures.

\section{Conclusion}

In this study, $\mathrm{ZnO}$ nanoparticles and QDs nanostructures as nanospherical and nanorods arrays were fabricated by sol-gel, wet-chemical, and hydrothermal methods. Audible sound including microwave process as unreported and new procedure for biosynthesis of zinc oxide nanoparticles ( $\mathrm{ZnO}$ NPs) was used as novel method. PVP and oleic acid as capping agent showed that they could modify and activate the wide surface of nanoZnO structures. In this case, they can have more contact with bacteria and the efficiency will enhance. These studies demonstrate that the especial $\mathrm{ZnO}$ QDs nanoparticles including blue shifts spectrums and complex defects on surfaces exhibit 
Table 3. Presentation of activity for ZnO NPs aiding of assisted agents and pretreatment.

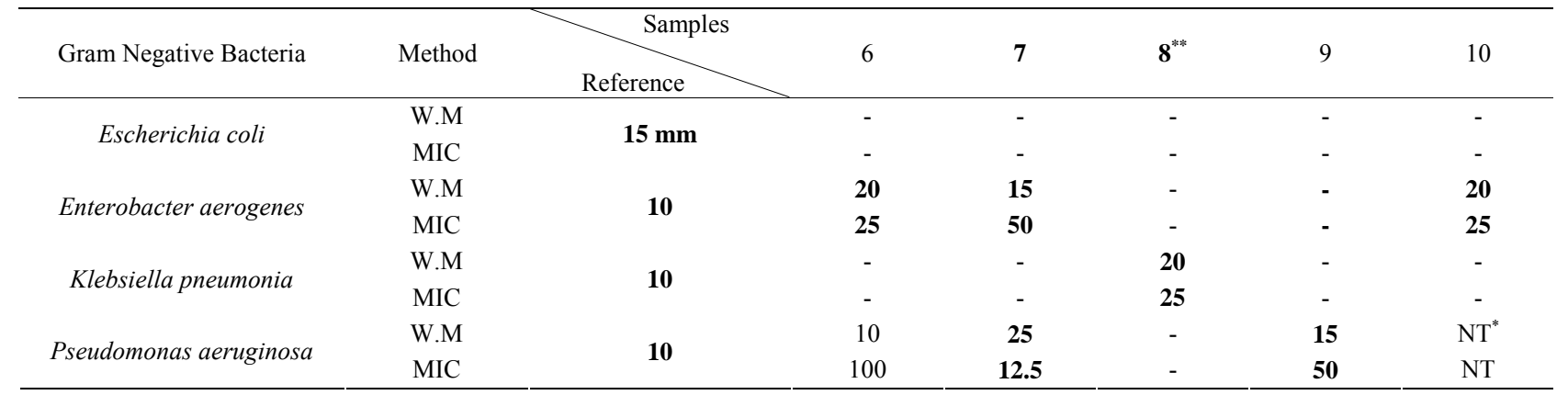

$\mathrm{NT}^{*}=$ was not done.

Table 4. Investigation of antimicrobial activity of the various ZnO NPs against Gram positive bacteria.

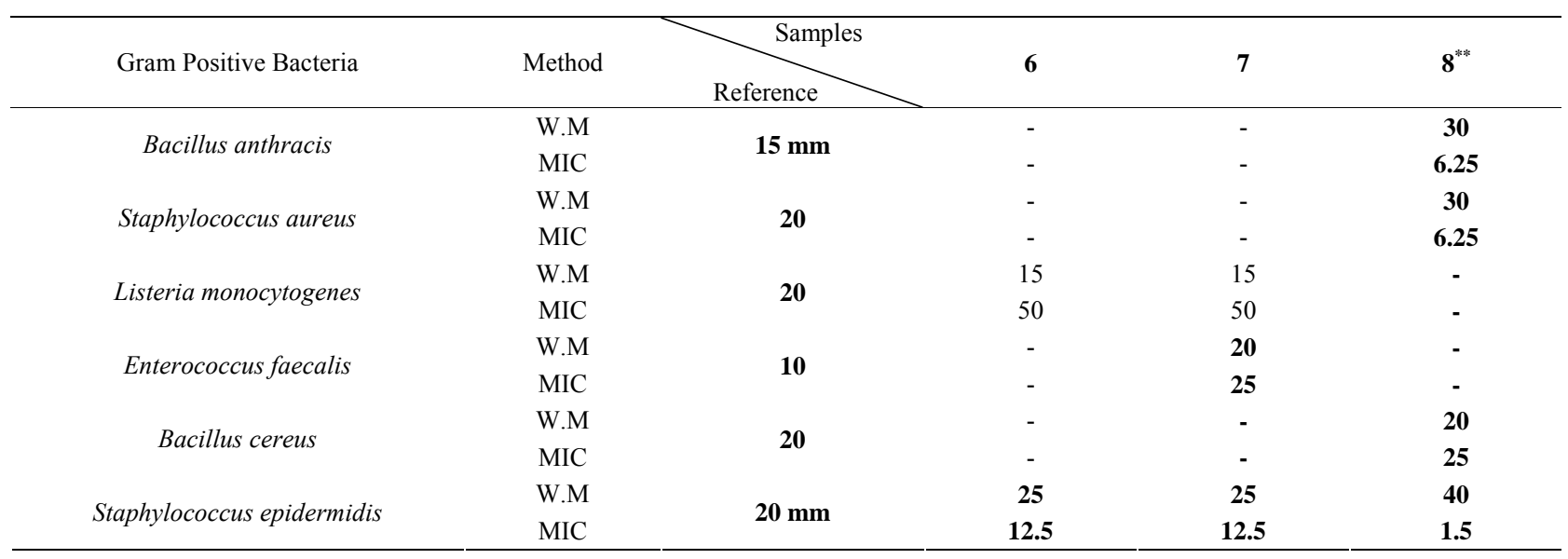

a wide range of antibacterial activities toward various microorganisms compared to standard antibiotic. Besides, our finding confirmed that the shape, structure, morphology and the kind of fabrication products (carry a positive charge) were effective in high performance of microorganisms with negative charge which can create an electromagnetic attraction between the microbe and treated QDs $\mathrm{ZnO}$ surface and eventually causing the cellular death. Furthermore, the QDs link to a photosensitizer is used for photodynamic cancer therapy. Our observation confirmed that sample 11 contains citric acid showed prominent activity as antibacterial against Bacillus cereus (RTCC1040 gr+), but none of our samples had sensitive stress responses to Listeria monocytogenes

(RITCC1293 gr+). In addition, the efficacy of antibacterial activity of significant nanorods of sample 12 (cold quenching) is not known up to now for us and needs to detect many alternative bacteria tests.

\section{Acknowledgements}

The authors are deeply grateful to Mrs. Narges Mohammadi for spectrometry and Prof. Alexander M. Seifalian and Dr. Yazdan Madani from UCL, UK owing to encourage us in continuing project. Also, authors would like to thank Mrs. Daneshi and Ahmadi from PTS.

\section{REFERENCES}

[1] L. E. Greene, B. D. Yuhas, M. Law, D. Zitoun and P. Yang, "Solution-Grown Zinc Oxide Nanowires," Inorganic Chemistry, Vol. 45, No. 19, 2006, pp. 7535-7543.

[2] F. Li, W. Bi, L. Liu, Z. Li and X. Huang, "Preparation and Characterization of $\mathrm{ZnO}$ Nanospindles and $\mathrm{ZnO} @$ ZnS Core-Shell Microspindles," Colloids and Surfaces A, Vol. 334, No. 1-3, 2009, pp. 160-164. doi:10.1016/j.colsurfa.2008.10.016

[3] T. Jin, D. Sun, J. Y. Su, H. Zhang and H. J. Sue, “Antimicrobial Efficacy of Zinc Oxide Quantum Dots against Listeria monocytogenes, Salmonella Enteritidis, and Escherichia coli O157:H7," Journal of Food Science, Vol. 74, No. 1, 2009, pp. M46-M52. doi:10.1111/j.1750-3841.2008.01013.x

[4] D. Zvekić, V. V. Srdić, M. A. Karaman and M. N. Matavulj, "Antimicrobial Properties of ZnO Nanoparticles Incorporated in Polyurethane Varnish," Processing and Application of Ceramics, Vol. 5, No. 1, 2011, pp. 41-45.

[5] T. Alammar and A. V. Mudring, "Facile Ultrasound-Assisted Synthesis of $\mathrm{ZnO}$ Nanorods in an Ionic Liquid," Materials Letters, Vol. 63, No. 9-10, 2009, pp. 732-735. doi:10.1016/j.matlet.2008.12.035

[6] Y. Tian, H. Ma, L. Shen, Z. Wang, Y. Qu and S. Li, "Novel and Simple Synthesis of ZnO Nanospheres through Decomposing Zinc Borate Nanoplatelets," Materials Letters, Vol. 63, No. 12, 2009, pp. 1071-1073. 
doi:10.1016/j.matlet.2009.02.009

[7] Y. Zeng, T. Zhang and L. Qiao, "Preparation and Gas Sensing Properties of the Nutlike ZnO Microcrystals via a Simple Hydrothermal Route," Materials Letters, Vol. 63, No. 11, 2009, pp. 843-846. doi:10.1016/j.matlet.2009.01.012

[8] M. L. Singla, M. Shafeeq and M. Kumar, "Optical Characterization of $\mathrm{ZnO}$ Nanoparticles Capped with Various Surfactants," Journal of Luminescence, Vol. 129, No. 12, 2009, pp. 434-438. doi:10.1016/j.jlumin.2008.11.021

[9] K. Senthilkumar, M. Tokunaga, H. Okamoto, O. Senthilkumar and Y. Fujita, "Hydrogen Related Defect Complexes in ZnO Nanoparticles," Applied Physics Letters, Vol. 97, No. 9, 2010,Article ID: 091907. doi:10.1063/1.3485049

[10] X. Xu, C. Xu, J. Dai, J. Hu, F. Li and S. Zhang, "Size Dependence of Defect-Induced Room Temperature Ferromagnetism in Undoped ZnO Nanoparticles," The Journal of Physical Chemistry C, Vol. 116, No. 15, 2012, pp. 8813-8818. doi:10.1021/jp3014749

[11] H. Q. Shi, W. N. Li, L.W. Sun, Y. Liu, H. M. Xiao and S. Y. Fu, "Synthesis of Silane Surface Modified ZnO Quantum Dots with Ultrastable, Strong and Tunable Luminescence," Chemical Communications, Vol. 47, No. 43, 2011, pp. 11921-11923. doi:10.1039/c1cc15411g

[12] K. H. Tam, A. B. Djurisic, C. M. N. Chan, Y. Y. Xi, C. W. Tse, Y. H. Leung, W. K. Chan, F. C. C. Leung and D. W. T. Au, "Antibacterial Activity of ZnO Nanorods Prepared by a Hydrothermal Method," Thin Solid Films, Vol. 516, No. 18, 2008, pp. 6167-6174. doi:10.1016/j.tsf.2007.11.081

[13] Y. Xie, Y. He, P. L. Irwin, T. Jin and X. Shi, "Antibacterial Activity and Mechanism of Action of Zinc Oxide Nanoparticles against Campylobacter jejuni," Applied and Environmental Microbiology, Vol. 77, No. 7, 2011, pp. 2325-2331. doi:10.1128/AEM.02149-10

[14] N. Padmavathy and R. Vijayaraghavan, "Enhanced Bioactivity of ZnO Nanoparticles an Antimicrobial Study," Science and Technology of Advanced Materials, Vol. 9, No. 3, 2008, Article ID: 035004. doi:10.1088/1468-6996/9/3/035004

[15] L. Zhang, Y. Ding and Y. L. D. Cang, "Antimicroorganism Activities Comparison among $\mathrm{ZnO}, \mathrm{TiO}_{2}, \mathrm{MgO}$ and $\mathrm{SiO}_{2}$ Nanoparticles Suspensions at Different pH Values," The 2nd International Conference on Chemical, Biological and Environmental Engineering, 2010, pp. 257-260.

[16] A. A. Tayel, W. F. EL-Tras, S. Moussa, A. F. EL-Baz, H. Mahrous, M. F. Salem and L. Brimer, "Antibacterial Action of Zinc Oxide Nanoparticles against Foodborne Pathogens," Journal of Food Safety, Vol. 31, No. 2, 2011, pp. 211-218. doi:10.1111/j.1745-4565.2010.00287.x

[17] R. O. Moussodia, L. Balan, C. Merlin, C. Mustin and R. Schneider, "Biocompatible and Stable $\mathrm{ZnO}$ Quantum Dots Generated by Functionalization with Siloxane-Core PAMAM Dendrons," Journal of Materials Chemistry, Vol. 20, No. 6, 2010, pp. 1147-1155. doi:10.1039/b917629b

[18] M. Premanathan, K. Karthikeyan, K. Jeyasubramanian and G. Manivannan, "Selective Toxicity of $\mathrm{ZnO}$ Nanoparticles toward Gram-Positive Bacteria and Cancer Cells by Apoptosis through Lipid Peroxidation," Nanomedicine: Nanotechnology, Biology and Medicine, Vol. 7, No. 2, 2011, pp. 184-192. doi:10.1016/j.nano.2010.10.001

[19] G. Singh, E. M. Joyce, J. Beddow and T. J. Mason, "Evolution Antibacterial Activity of $\mathrm{ZnO}$ Nanoparticles Coated Sonochemically onto Textile Fabrics," Journal of Microbiology, Biotechnology and Food Sciences, Vol. 2, No. 1, 2012, pp. 106-120.

[20] Z. E. Karvani and P. Chehrazi, "Antibacterial Activity of ZnO Nanoparticle on Gram-Positive and Gram Negative Bacteria," African Journal of Microbiology Research, Vol. 5, No. 12, 2011, pp. 1368-1373. doi:10.5897/AJMR10.159

[21] O. Yamamoto, "Influence of Particle Size on the Antibacterial Activity of Zinc Oxide," International Journal of Inorganic Materials, Vol. 3, No. 7, 2001, pp. 643-646.

[22] T. Phaechamud, J. Mahadlek, N. Aroonrerk, S. Choopun and J. Charoenteeraboon, "Antimicrobial Activity of $\mathrm{ZnO}$ Doxycycline Hyclate Thermosensitive Gel," Science Asia, Vol. 38, No. 1, 2012, pp. 64-74.

doi:10.2306/scienceasia 1513-1874.2012.38.064

[23] S. Kumar and P. D. Sahare, "Effects of Annealing on the Surface Defects of Zinc Oxide Nanoparticles," Nano: Brief Reports and Reviews, Vol. 7, No. 3, 2012, Article ID: 1250022. doi:10.1142/s1793292012500221

[24] M. H. Wong, A. Berenov, X. Qi, M. J. Kappers, Z. H. Barber, B. Illy, Z. Lockman, M. P. Ryan and J. L. M. Driscoll, "Electrochemical Growth of ZnO Nano-Rods on Polycrystalline Zn Foil," Nanotechnology, Vol. 14, No. 9, 2003, pp. 968-973.

[25] D. Bera, L. Qian, S. Sabui, S. Santra and P. H. Holloway, "Photoluminescence of ZnO Quantum Dots Produced by a Sol-Gel Process," Optical Materials, Vol. 30, No. 8, 2008, pp. 1233-1239. doi:10.1016/j.optmat.2007.06.001

[26] A. Saric, S. Music and M. Ivanda, "Varying the Microstructural Properties of $\mathrm{ZnO}$ Particles Using Different Synthesis Routes," Journal of Molecular Structure, Vol. 993, No. 1-3, 2011, pp. 219-224.

doi:10.1016/j.molstructruc.2010.10.018

[27] R. Sreeja, Jobina John, P. M. Aneesh and M. K. Jayaraj, "Linear and Nonlinear Optical Properties of Luminescent ZnO Nanoparticles Embedded in PMMA Matrix," Optics Communications, Vol. 283, No. 14, 2010, pp. 2908-2913.

[28] H. M. Cheng, H. C. Hsu, S. L. Chen, W. T. Wu, C. C. Kao, L. J. Lin and W. F. Hsieh, "Efficient UV Photoluminescence from Monodispersed Secondary ZnO Colloidal Spheres Synthesized by Sol-Gel Method," Journal of Crystal Growth, Vol. 277, No. 1-4, 2005, pp. 192-199. doi:10.1016/j.jcrysgro.2004.12.133

[29] B. X. Hu, J. Gong, L. Zhang and J. C. Yu, "Continuous Size Tuning of Monodisperse ZnO Colloidal Nanocrystal Clusters by a Microwave-Polyol Process and Their Application for Humidity Sensing," Advanced Materials, Vol. 20, No. 24, 2008, pp. 4845-4850. doi:10.1002/adma.200801433

[30] S. Y. Kuo, F. I. Lai, W. C. Chen, C. P. Cheng, H. C. Kuo and S. C. Wang, "Ultraviolet Lasing of Sol-Gel-Derived Zinc Oxide Polycrystalline Films," Japanese Journal of Applied Physics, Vol. 45, No. 4B, 2006, pp. 3662-3665. doi:10.1143/JJAP.45.3662 
[31] K. F. Lin, H. M. Cheng, H. C. Hsu, L. J. Lin and W. F. Hsieh, "Band Gap Variation of Size-Controlled $\mathrm{ZnO}$ Quantum Dots Synthesized by Sol-Gel Method," Chemical Physics Letters, Vol. 409, No. 4-6, 2005, pp. 208-211. doi:10.1016/j.cp1ett.2005.05.027

[32] C. Valgas, S. M. de Souza, E. F. Smania and A. Smania Jr., "Screening Methods to Determine Antibacterial Activity of Natural Products," Brazilian Journal of Microbiology, Vol. 38, No. 2, 2007, pp. 369-380.

[33] European Committee for Antimicrobial Susceptibility Testing (EUCAST) of the European Society of Clinical Microbiology and Infectious Diseases (ESCMID), "Determination of Minimum Inhibitory Concentrations (MICs) of antibacterial agents by agar dilution," Clinical Microbiology and Infection, Vol. 6, No. 9, 2000, pp. 509515.
[34] F. Arabi, M. Imandar, M. Negahdary, M. Imandar, M. Torkamani Noughabi, H. Akbari dastjerdi and M. Fazilati, "Investigation Anti-Bacterial Effect of Zinc Oxide Nanoparticles upon Life of Listeria monocytogenes," Annals of Biological Research, Vol. 3, No. 7, 2012, pp. 3679-3685.

[35] K. Chitra and G. Annadurai, "Antimicrobial Activity of Wet Chemically Engineered Spherical Shaped ZnO Nanoparticles on Food Borne Pathogen," International Food Research Journal, Vol. 20, No. 1, 2013, pp. 59-64.

[36] J. M. Yousef and E. N. Dania "In Vitro Antibacterial Activity and Minimum Inhibitory Concentration of Zinc Oxide and Nano-Particle Zinc Oxide against Pathogenic Strains," Journal of Health Science, Vol. 2, No. 4, 2012, pp. 38-42. doi:10.5923/j.health.20120204.04 